Narrative Review

\title{
Q Prescription Opioid Use, Harms and Interventions in Canada: A Review Update of New Developments and Findings since 2010
}

\author{
Yoko Murphy, BA 1 , Elliot M. Goldner, $\mathrm{MD}^{2}$, and Benedikt Fischer, $\mathrm{PhD}^{1-4}$
}

From: ${ }^{1}$ Social \& Epidemiological Research, Centre for Addiction \& Mental Health (CAMH),

Toronto, Ontario, Canada

${ }^{2}$ Centre for Applied Research in Mental Health and Addictions (CARMHA), Faculty of Health Sciences, Simon

Fraser University, Vancouver, British Columbia, Canada; 3Department of Psychiatry, University of Toronto, Toronto, Ontario, Canada ; 4 Institute of Medical Science, University of Toronto, Toronto, Ontario, Canada

Address Correspondence: Benedikt Fischer, PhD Senior Scientist

Department of Social and Epidemiological Research Centre for Addiction and Mental Health (CAMH) Professor, Dept. of Psychiatry, University of Toronto

CIHR/PHAC Applied Public Health Chair

33 Russell St., Toronto, Ontario, $\mathrm{M}_{5} \mathrm{~S}_{2} \mathrm{~S}_{1}$, Canada

E-mail: bfischer@sfu.ca

Disclaimer: There was no external funding in the preparation of this manuscript.

Conflict of interest: Each

author certifies that he or

she, or a member of his or her immediate family, has no commercial association (i.e., consultancies, stock ownership, equity interest, patent/

licensing arrangements, etc.)

that might pose a conflict of

interest in connection with the

submitted manuscript.

Manuscript received: 02-14-2015

Revised manuscript received: 03-17-2015

Accepted for publication: 03-20-2015

Free full manuscript: www.painphysicianjournal.com
Background: Canada has featured the second-highest levels of prescription opioid (PO) use globally behind the United States, and reported extensive PO-related harms (e.g., non-medical PO use [NMPOU], PO-related morbidity and mortality). A recent comprehensive review synthesized key data on PO use, PO-related harms, and interventions in Canada, yet a substantive extent of new studies and data have emerged.

Objective: To conduct and present a comprehensive review update on PO use, PO-related harms, and interventions in Canada since 2010.

Study Design: Narrative review

Methods: We conducted literature searches, employing pertinent keywords, in key databases, focusing on PO-related studies/data in/for Canada since 2010, or pertinent studies/data from earlier periods not included in our previous review. In addition, we identified relevant data from "grey" literature (e.g., government, survey, other data or system reports). Relevant data were screened and extracted, and categorized into 4 main sections of indicators: 1) PO dispensing and use, 2) non-medical PO use, 3) PO-related morbidity/mortality, 4) PO-related interventions and impacts.

Results: PO-dispensing in Canada overall continued to increase and/or remain at high levels in Canada from 2010 to 2013, with the exception of the province of Ontario where marked declines occurred starting in2012; quantitative and qualitative PO dispensing patterns continued to vary considerably between provinces. Several studies identified common "high PO dosing" prescribing practices in different settings. Various data suggested declining NMPOU levels throughout most general (e.g., adult, students), yet not in special risk (e.g., street drug users, First Nations) populations. While treatment demand in Ontario plateaued, rising PO-related driving risks as well as neo-natal morbidity were identified by different studies. PO-related mortality was measured to increase - in total numbers and proportionally - in various Canadian jurisdictions. Select reductions in general PO and/or high-dose PO dispensing were observed following key interventions (e.g., Oxycodone delisting, prescription monitoring program [PMP] introduction in Ontario/British Columbia). While physician education intervention studied indicated mixed outcomes, media reporting was found to be associated with PO prescribing patterns.

Limitations: The present review did not utilize systematic review standards or meta-analytic techniques given the large heterogeneity of data and outcomes reviewed.

Conclusions: Recently emerging data help to better characterize PO-related use, harm and intervention indicators in Canada's general context of comparatively high-level PO dispensing and harms, yet major gaps in monitoring and information persist; this continues to be a problematic challenge, especially given the implementation of key PO-related interventions post-2010, the impact of which needs to be properly measured and understood.

Key words: Prescription opioids, use, dispensing, dosing, education, non-medical use, Canada, morbidity, mortality, monitoring, interventions, policy, review

Pain Physician 2015; 18:E605-E614 
P rescription opioid (PO) misuse and related harms have risen to constitute a major public health problem and policy challenge since the start of the present century. This problem has been most prominent in North America, where Canada, in global comparison, has featured levels of PO use and related problem indicators that are second only (but proportionally similar) to the United States (US) (2-4). Recent reviews focusing on the US have shown that key problem indicators - for example, misuse especially of strong PO, PO-related emergency room and/or treatment admissions, fatal poisoning incidents - have shown multifold increases alongside similar trends for overall dispensing volumes of POs in the first millennial decade (2000 - 2010), although these increases slowed or plateaued in more recent years and have begun to decrease for select indicators since then $(5,6)$. A recent (2010) review (1) comprehensively summarized key indicators and developments on PO dispensing/use and non-medical use, harm and policy/interventions available for Canada at the time. Based on key developments and changes in these various areas, and the quick evolution of relevant scientific knowledge and data, we are presenting an updated review of this important topic. Our review principally focuses on new data generated or analyses conducted since 2010 with a primary focus on Canada, or information that had otherwise not been included in the original review.

\section{Methods}

We conducted searches, employing pertinent key words, in key literature databases, focusing on studies that presented data on PO use or non-medical use, PO-related morbidity or mortality indicators, as well as PO-related interventions and their impact specifically focusing on Canada since 2010, or pertinent studies conducted since 2010 involving data from earlier study periods that had not been included in the previous review (1). In addition, we manually identified relevant data from "grey" literature (e.g., government, survey, other data or system reports). Data were principally extracted by one of the authors (YM), and reviewed by at least one of the authors, especially in cases of discordance of interpretation. Information and data extracted were thematically categorized and narratively presented into the 4 main sections: 1) PO dispensing or use, 2) non-medical PO use, 3) PO-related morbidity/ mortality indicators, 4) PO-related interventions and impacts; these were further categorized into additional sub-sections as meaningful for structured presentation.
Given the extensive heterogeneity of indicator and outcome data reviewed, systematic review techniques or meta-analytic techniques were not employed in the present review.

\section{Results}

\section{PO Dispensing and Medical Use General Populations}

Canada reported an annual consumption of 29,743 Defined Daily Doses (DDD) of POs per 1,000,000 population/day in the period 2010 - 2012 (7), an increase of $12.7 \%$ over 2008 - 2010 and a national PO consumption rate that is second only to the US (51,873 DDD) in global comparison. Complementary data similarly indicate that overall expenditures (per capita) for PO drugs increased from $\$ 18.96(2007 / 08)$ to $\$ 20.54$ $(2012 / 13 ;+8.3 \%)$ in Canada; there was a total of $\$ 717$ million in drug-store based PO-sales in 2012/13, based on 380 - 460 (per 1,000) PO prescriptions (8). Quantitative and qualitative PO dispensing patterns - based on data from a representative sample of retail pharmacies in Canada's 10 provinces - indicate that dispensing of "weak POs" slightly fell from 12.2 DDD/1,000 in 2010 to 11.7 DDD/1,000 in 2013; dispensing of "strong POs" remained overall stable (10.8 to 10.9) - albeit with interim increases - for Canada totals (9). In inter-provincial comparisons, overall rates for PO dispensing and expenditures remained highest in the provinces of Alberta and Ontario, while they are lowest in Quebec (variances by approximately factor 2); PO dispensing levels remained stable or slightly increased in all provinces except for Ontario - Canada's most populous province - where these levels decreased by approximately $20 \%$ from 2010 to $2013(8,9)$. Fentanyl, oxycodone, and methadone were the overall most prevalently consumed PO formulations (per DDDs) in Canada, although qualitative PO drug consumption patterns varied greatly between provinces $(8,9)$.

High-dose (> 200mg daily) PO dispensing were found to have increased by $23 \%$ across Canada from a rate of 781 units of high-dose PO prescriptions/1000 population in 2006 to 961/1000 population in 2011, varied by province including fairly moderate increases in Alberta (6.3\%) and BC (8.4\%), but considerable increases in Saskatchewan (54\%) and Newfoundland $(84.7 \%)(10)$. In units per 1,000 population, the greatest high-dose dispensing rates were found for oxycodone tablets (756) and fentanyl patches (112) in Ontario; morphine tablets (347) in Alberta; hydromorphone 
tablets in Nova Scotia (369) and Saskatchewan (258); in contrast, Quebec recorded the lowest high-dose dispensing of oxycodone (98) and morphine tablets (53) in the nation (10).

Based on self-report data from the Canadian Alcohol and Drug Use Monitoring Survey (CADUMS) representative for the Canadian general adult population, there was a nominal decline in self-reports for "any PO use" - from $20.6 \%$ in 2010 to $16.9 \%$ in 2012; no significant differences are reported for gender, age groups, or province (11). Similarly, the CAMH Monitorthe general adult population survey representative for the province of Ontario - reported a nominal decline of "any PO use" from $26.6 \%$ (2010) to $22.2 \%$ (2013) (12).

\section{Special Populations or Settings}

Among (provincial) public drug plan recipients mostly individuals on social assistance programs - across Canada, $12 \%-20 \%$ of beneficiaries had at least one PO claim/year in the period 2006/07 - 2012/13; the number of PO claims increased significantly over time in most plans. Weak POs accounted for $40 \%$ of all PO claims, $13 \%$ of morphine equivalents and $9 \%$ of PO drug costs; strong PO use was dominated by oxycodone and hydromorphone, accounting for $45 \%$ and $61 \%$, respectively, in 2012/13. Combined, the number of claims for these 2 drugs grew by $61 \%$ in terms of PO claims $/ 1000$ beneficiaries in the examination period. About $60 \%$ of provincial drug plan claimants made only one or 2 claims/ year, receiving mainly weak POs, whereas high-use PO claimants made $>10$ claims per year, representing $10 \%$ to $19 \%$ of all PO claimants, responsible for $47 \%$ to $69 \%$ of all PO claims and $83 \%$ of morphine equivalents dispensed. Over time, the utilization of strong POs increased for all claimants through the observation period (13).

Among public drug plan beneficiaries in Ontario, PO prescribing rates rose by $16.2 \%$ in the period $2003-$ 2008. Among 1.5 million PO prescriptions dispensed in 2008 , the daily dose was $>200 \mathrm{mg}$ morphine equivalent for a third $(32.6 \%)$ of recipients of long-acting oxycodone but only $20.3 \%$ of those treated with fentanyl or other long-acting POs (14). A 2010 survey of family physicians who prescribe POs for non-cancer pain across Canada revealed that $73 \%(n=643)$ usually continued to prescribe POs to patients who reported insufficient relief; of 710 physicians, a mere $5 \%$ correctly identified the "watchful dose" of POs; and only 2 of 9 knowledge questions were answered correctly by $>40 \%$ of respondents - these results were despite a new guideline for PO prescribing having been accessible during the 6-month duration of the survey (15). In Ontario in 2003 -2010 , a study of PO-naïve patients $(n=39,140)$ found $49.2 \%$ were prescribed opioids after elective surgery, and $3.1 \%$ exhibited prolonged $\mathrm{PO}$ use for $>90$ days after elective surgery (16). Provincial health records in Manitoba indicated that $3.8 \%$ of total PO dosages dispensed to persons aged 18 - 65 went to Workers Compensation Board (WCB) claimants in 2010, compared to $1.8 \%$ in 1998; WCB claimants were also more likely to be prescribed $\geq 120$ morphine equivalents/day (11.8\%) than other Manitobans (5.8\%) (17).

PO use among a sample of cancer-related decedents was monitored in Quebec in 2003 - 2008 ( $n=$ 48,420 ), where an earlier start of PO-based therapy was associated with a higher daily dose of morphine equivalence; a small proportion of patients (5.2\%) who were already filling PO prescriptions in communitybased pharmacies at study entry were found with a final dose of $>300 \mathrm{mg}$ at time of death (18). Among the methadone maintenance treatment (MMT) population in British Columbia (BC) ( $n=16,248), 34.2 \%$ of patients received $\mathrm{PO}$ co-prescriptions (i.e., receiving $>7$ days of a PO other than methadone) during enrollment in MMT in 1996 - 2007, a finding similar to high rates of coprescriptions recently observed among MMT recipients in Ontario $(19,20)$. The majority of PO co-prescriptions $(74.3 \%)$ in BC were obtained from non-MMT physicians; PO prescriptions per person-year nearly doubled during the study period (3.7 to 6.8), largely due to increases in morphine, hydromorphone, and oxycodone co-prescriptions (20). Among a sample of injection drug users (IDUs) reporting pain $(n=462)$ from 2 Vancouver cohorts in 2011 - 2013, 66.5\% recalled ever being denied prescription analgesics; this experience was positively associated with daily cocaine injection or ever being in MMT, and most commonly reported as due to being accused of drug-seeking (21). In addition, the denial of PO prescriptions commonly resulted in them buying POs $(40.1 \%)$ and heroin $(32.9 \%)$ off the street to treat pain (21).

\section{Non-medical Prescription Opioid Use General Populations}

The CADUMS originally measured PO abuse "to get high," and only recently expanded the definition of abuse to include if POs were used to feel better, study, stay alert, decrease appetite, cope with stress, problems, or any other reason (22). Under these parameters, PO abuse was reported by $0.9 \%$ of general popu- 
lation adults (5.2\% of self-identified users of any POs) in the 2012 CADUMS, a significant increase from 2011 rates $(0.1 \% / 1.3 \%)$ (11). The CAMH Monitor recorded significant decreases in rates of non-medical $\mathrm{PO}$ use (NMPOU) among Ontario adults, from 7.7\% (2010) to $4 \%$ (2011) and 2.8\% (2013); this reduction was observed across almost all demographic sub-groups except ages 18 - 29 years where rates remained unchanged (12). Further analyses found associations between NMPOU and cannabis use among male adults, and binge drinking among female adults in Ontario (23). In Alberta, a random, representative sample of adults $(n=3,511)$ surveyed in 2002 found prescription drug misuse at $8.2 \%$, of which POs were the most common (4.9\%); past-year alcohol dependence and illicit drug use were associated with prescription medication misuse, and disability status was the strongest overall predictor of misuse (24).

\section{Student Populations}

The national Youth Smoking Survey indicated that $2.8 \%$ (range $1.5 \%-4.0 \%$ ) of students (grades $7-12$ ) across Canada had used pain relievers in the past year "to get high" in 2012/13, a significant decrease from previous years (3.9\% in 2010/11 and $4.5 \%$ in 2008/09) (25). The Ontario Student Drug Use and Health Survey (OSDUHS) reported in 2013 that NMPOU was perceived as drug use carrying the highest risk for harm by Ontario students in grades $9-12$, and as the second highest after regular marijuana use among grade 7 - 8 students; NMPOU was reported across the grades at $12.4 \%$ in 2013 and $14.0 \%$ in 2011, constituting significant decreases from $20.6 \%$ in 2007 (26). NMPOU prevalence increased with grade level, peaking at $16.1 \%$ among grade 12 students; however, there was no significant difference in NMPOU by gender, while it was associated with other drug use among both genders $(23,26)$.

Among grade 7 - 12 students in the British Columbia Adolescent Health Survey, 11\% in 2013 (down from 15\% in 2008) reported prescription pill use without doctor's consent; this data likely mainly reflected, but was not limited to, POs (27). Students were more likely to have used prescription pills non-medically if they also used alcohol or drugs to deal with stress. The combined Nova Scotia, Newfoundland, and New Brunswick Student Drug Use Surveys found rates of non-medical prescription pain reliever use in the past year between $9.8 \%$ and $11.7 \%$ among students grades $7-12$ in 2012, second only to cannabis use in regards to illicit drug use rates (28-30). In Prince Edward Island, the latest survey data (2010/11) reported that $4.6 \%$ of students had used prescription pain relievers to get high in the past year (31).

\section{Special Populations}

The Public Health Agency of Canada's I-Track Survey (Phase II) examined drug use behaviors of IDUs in 10 pan-Canadian sites (2005 - 2008). In the 6 months prior to assessment, participants reported NMPOU via injection of non-prescribed morphine (40.4\% in Phase II vs. $45.9 \%$ in Phase I, 2003 - 2005), oxycodone (39\% vs. $17.1 \%)$, and hydromorphone $(26.5 \%$ vs. $32.9 \%)$; non-injection NMPOU was reported for Tylenol with codeine $(26.4 \%$ vs. $51.5 \%)$, oxycodone $(22.4 \%$ vs. $27.8 \%)$, hydromorphone $(22.4 \%$ vs. $23.6 \%)$, and morphine (21.4\% vs. $31.1 \%)$; however, major differences in individual PO prevalence were reported by site $(32,33)$. Eighteen point eight percent of a cohort of street-level sex workers in Vancouver in 2010 - 2013 ( $n=692$ ) reported NMPOU in the last 6 months, and NMPOU was found to correlate with police harassment/arrest, injection drug use, and recent intimate partner physical or sexual violence (34). In a correctional inmate sample (n = 499) from a provincial jail in Ontario assessed in 2009, $35 \%$ - multifold the rate of heroin use - reported the illicit use of POs in the year prior to incarceration; $30 \%$ used POs by injection (35).

The Regional Health Survey (RHS) for First Nations/ Aboriginal (FNA) populations on reserves and in Northern Canada found past-year illicit opioid use (including heroin) among adults at a rate of $4.7 \%$ in $2008-2010$; rates were elevated among those with a chronic health condition (5.0\%) and the rate reported by youth was $1.3 \%$ (36). NMPOU was reported by up to $50 \%$ of the population in many Nishnawbe Aski Nation communities in northern Ontario (37). Analysis of the Youth Smoking Survey (2008/09) found NMPOU to be more common among FNA/Metis/Inuit students compared to other students; it also observed an association between school connectedness and a reduction in NMPOU (38).

\section{Morbidity and Mortality}

In the absence of national monitoring systems and data, select PO-related morbidity and mortality indicators exist mainly relying on provincial databases and studies since 2010.

\section{PO-related Morbidity}

Annual reported PO-related treatment admissions to publicly funded treatment services in Ontario documented by The Drug and Alcohol Treatment Information System (DATIS) slightly fell to 18,364 (17.2\% of total 
admissions) in 2012/13, from 21,448 (19.6\%) in 2011/12 and 20,374 (18.6\%) in 2010/11 (39). On a population level, strong correlations (0.99) between PO dispensing levels and PO-related treatment admission have been observed for Ontario in 2005 - 2011 (40). In a Vancouverbased cohort of IDUs, PO use was not independently associated with hepatitis $\mathrm{C}$ virus (HCV) sero-conversion in the period 2005 - 2011, a finding different from recent observations with IDUs in Montreal $(41,42)$. A study of sex workers in Vancouver in 2010 - 2013 indicated a correlation between NMPOU and sex-exchange practices while intoxicated (34), increasing sexual risk practices relevant to STD transmission. The incidence of opioidrelated neonatal abstinence syndrome in Ontario was found to have increased 15-fold, from 0.28 per 1000 births (1992) to 4.29 (2011); 927 births with neonatal abstinence syndrome were identified in $2006-2011$ to mothers who were public drug plan beneficiaries, $67 \%$ of whom had received a PO prescription - with about half involving methadone - in the 100 days preceding delivery (43). Data from prenatal clinics in a First Nations community in northwestern Ontario found PO use during pregnancy to have risen to $28.6 \%$ in 2013 (from $17.2 \%$ in 2010), though neonatal abstinence syndrome in narcotic-exposed infants fell to $18.0 \%$ (from $29.5 \%$ in 2010) $(44,45)$.

In Atlantic Canada, the 2012 Student Drug Use Survey found that $4.3 \%$ of students of eligible driving age in grades 10 and $12(n=3,655)$ had driven while under the influence of POs in the past year; among students with PO prescriptions ( $n=1,136), 14 \%$ who had any PO use in the last year and $25 \%$ of those using POs medically and recreationally reported driving while under the influence of POs (46). In an Ontario population sample of adults aged $18-64$ who received at least one publicly funded PO prescription ( $n=549,878$ ) in the period 2003 - 2011, about $1 \%$ were found to be involved in a road trauma incident; $P O$ dosage prescribed was found to be correlated with increased odds $(21 \%-42 \%)$ of road trauma among drivers compared to population controls, but not for other traffic participants (47).

\section{PO-Related Mortality}

The total number and the proportion of PO-related overdose deaths (ODs) of all drug-related deaths in Ontario both increased substantially from $173 / 513(33.7 \%)$ in 2002 to $540 / 751(71.9 \%)$ in $2012(48,49)$. Correspondingly, the rate of PO-related mortality in the Ontario population was analyzed to have increased significantly from 127 annual deaths (or $0.2 \%$ of all premature deaths) in 1991 to $550(0.6 \%$; $+242 \%)$; nearly 1 in 8 deaths in ages 25 - 34 (12.1\%) was PO-related in 2010 (50). In a review of characteristics of drug-related ODs in Ontario in $2006-2008$ ( $n=2,330), 58 \%$ were attributed wholly or partly to opioids ( $n=1,359$ ), $35 \%$ of which involved oxycodone; the highest proportion of single opioid-related accidental ODs were seen related to methadone, hydromorphone, and fentanyl (51). Seven percent of all drug-related ODs involved POs prescribed to a friend or family member (51). For PO-related mortality in Ontario in the period 2005 - 2011, strong correlations were documented between annual levels of PO formulation-specific mortality and annual retail pharmacy-based dispensing for hydromorphone (0.98), fentanyl (0.93), and oxycodone (0.93) (52). Significant associations were found between PO prescribing (number of prescriptions dispensed/1,000 public drug plan beneficiaries aged 15 - 64) and PO-related mortality (deaths/100,000 population) in 2004 - 2006 on county levels in Ontario; specifically, it was found that for every additional PO prescription, the annual opioid-related mortality rate increased by 0.54 per 100,000 residents ( $P$ $<.0001)$ (53). Among public drug plan beneficiaries in Ontario, to whom high or very high doses of POs were dispensed in 2004, $19.3 \%$ of deaths during the subsequent 2 years were PO-related, occurring at a median age of 46 years; 2-year PO-related mortality rates continuously increased from $1.63 / 1000$ population $(95 \%$ $\mathrm{Cl} 1.42$ - 1.85) among people with moderate-dose, to $9.94 / 1000$ population $(95 \% \mathrm{Cl} 2.78-25.12)$ among those with very high-dose PO prescriptions (14).

Totals numbers of PO-related ODs rose in BC from 32 in 2005 to 50 in 2010, similar - and contributing - to increases in totals of illicit drug-related ODs (195 in 2009 to 279 in 2013); pronounced increases have recently been observed for fentanyl-related ODs (15 in 2012, 51 in 2013, and 27 in the first quarter of 2014) (54-56). Similar to Ontario, strong correlations between ODs and dispensing levels of select strong PO formulations (e.g., oxycodone, hydromorphone) were identified for BC in 2005 - 2009 (40). Opioids were found to be increasingly implicated in drug-related deaths in Quebec, involving an increase from 94 (36\%) opioid-related deaths/year in the period 2000 - 2004 to 152 (41\%) in 2005 - 2009; moreover, POs constituted an increasing proportion of opioid-related ODs, related to $82(85 \%)$ to $139(91 \%)$ annual drug deaths in the respective periods (57).

Thirty-six point seven percent of decedents ( $>65$ years) with colorectal cancer in palliative care programs in Nova Scotia in $2001-2008(n=657)$ had filled at least 
one PO prescription within 6 months prior to death (58).

\section{Interventions and Impacts}

Following the rapid increases in PO-related harms, a number of interventions aiming at these problems have been implemented in Canada on different fronts since 2010. New federal prescription guidelines for medical use of POs in non-cancer pain were launched in $2010(59,60)$. As part of targeted policy interventions to reduce PO-related harms in the population, a number of provinces delisted slow-release oxycodone formulations (e.g., Oxycontin, as well as its successor product, Oxy Neo) from their public drug formularies in early $2012(61,62)$. Ontario specifically implemented new narcotics control legislation and established a prescription monitoring program (PMP) in 2012, whereas other provinces sharpened the design or enforcement of relevant programs in the context of a heterogeneous array of - provincially run - PMPs across the country $(63,64)$. A "National Prescription Drug Misuse Strategy" was tabled on the federal level in 2013, whereas similar initiatives - mostly containing a multitude of measures and recommendations - were launched in select provincial jurisdictions $(65,66)$. Federal regulatory initiatives also stipulated new labelling requirements for PO medications, and new guidelines for tamper-proofing new PO formulations were drafted and subjected to consultations $(67,68)$. In addition, electronic and print mass media intensified their reporting on PO misuse and harms, and various aspects of this problem phenomenon $(69,70)$.

Since 2012, PO-related policy measures taken in Ontario (primarily: the delisting of slow and controlled oxycodone formulations from public formularies) have been associated with both substantively decreasing oxycodone dispensing levels (-45.0\% between 2011 and 2013) and NMPOU rates (significantly decreased from $4 \%$ to $2.8 \%$ between 2011 and 2013 ) in the population, although strict causal interpretations could not be made $(9,71)$. Dispensing levels of select other strong POs (e.g., fentanyl, hydromorphone) however increased and contributed to an - at least partial - "substitution effect" in other strong PO dispensing during this time (9). While a slight decrease in PO-related calls to a telephone hotline (ConnexOntario) and substance abuse treatment services pertaining to POs was documented by DATIS, no significant changes relevant to health care service utilization (e.g., PO-related emergency room visits or hospital admissions) were observed in Ontario following the Oxycontin delisting intervention $(39,72,73)$.
The introduction of a centralized PMP in BC ("PharmaNet") was retrospectively found to have resulted in an overall reduction of $32.8 \%$ in inappropriate PO prescriptions - i.e., defined as prescriptions issued/ filled by a different physician/pharmacy within 7 days of an original prescription for the same drug - among patients on social assistance or aged 65 and older, in the 6 months post-PMP introduction in 1995 (74). Following the Narcotics Safety and Awareness Act passed in Ontario (2011), inappropriate (i.e., co-occurring) PO prescriptions significantly declined by $12.5 \%$ (from $1.6 \%$ in October 2011 to $1.4 \%$ in April 2012); however, the implementation of the PMP shortly thereafter (May 2012) did not result in further significant changes (75). While PMPs in effect on provincial levels across Canada differ considerably in design, scope, and operations (63), the Nova Scotia PMP identified the 30 (2.4\%) practitioners (responsible for $25 \%$ of prescriptions and $40 \%$ of dispensed tablets) prescribing the highest amounts of meperidine in 2006-2007 and conducted an audit of prescribing practices and implemented an educational intervention; compared to the 2 years pre-intervention (2005 - 2007), a decrease in the number of patients redeeming meperidine prescriptions $(-12.4 \%)$, meperidine prescriptions $(-10 \%)$, and meperidine tablets $(-13.5 \%)$ was observed in $2007-2009$ (76).

Data on a sample of PO-prescribing physicians ( $=138$ ) completing a 2 -day narcotics prescribing course in Toronto between 2000 and 2008 were matched to a control group; self-referred physicians $(68.1 \%)$ recorded no change in PO prescribing practices, while those referred to the course by the College of Physicians and Surgeons of Ontario (31.9\%) - e.g., after an investigation, public complaint, or peer assessment in regards to their prescribing - recorded a decreased rate of PO prescribing from the year prior to completion of the course compared to the control group; the decrease was sustained in the following 2 years (77). A feasibility study conducted in Sioux Lookout, Ontario, determined that an educational workshop on safe PO prescribing with family physicians $(n=18)$ was a well-received intervention and at one-year follow-up, physicians reported significantly less concerns about getting patients addicted to POs and difficulties with PO dosing (78).

Among prescribers $(n=4,212)$ in Nova Scotia in 1996 - 2007, correlations were found between prescribing practices and newspaper coverage of extended-release oxycodone; increases in respective prescribing volumes slowed when American news coverage peaked (2001), 
and began to decline when Canadian news coverage peaked (2004) through to the end of the study (2007) (70). Following the introduction of a tamper-resistant formulation of oxycodone (OxyContin-OP) in the US in August 2010, a 4-fold increase (from 505 to 1,969 tablets/1000 population), in dispensing of the original controlled-release formulation (OxyContin) was observed at Canadian pharmacies near the Detroit-Windsor Tunnel - a main US/Canada border crossing - in the following months, though dispensing reverted to 2010 levels after that; stable dispensing rates were recorded at pharmacies near other border crossings (79).

Buprenorphine/naloxone combination drugs ("Suboxone") were approved by Health Canada - also as a potential alternative to methadone as an opioid substitution treatment agent specifically in cases involving POs - for the treatment of opioid dependence in 2007. While clinical guidelines for therapeutic buprenorphine/ naloxone combination use were released in 2011, Canada-based treatment studies for PO-related disorders are virtually non-existent (80). Kanate et al (81) documented a community-based treatment intervention developed specifically for FNA populations in northern Ontario, where rates of $\mathrm{PO}$ misuse have been documented to be high, involving both FNA-culture based "healing" (e.g., counselling) strategies and buprenorphine-naloxone pharmacotherapy. Treatment involved $n=140$ selfidentified (largely prescription) opioid users since 2012; one year following program implementation, substantial reductions in crime problems, drug-related medical evaluations, and child protection cases, and increases in school attendance, vaccinations, and economic activity - all interpreted as improvements in community health indicators - were reported. Narcotic exposure was reported among $28 \%$ of births $(n=166)$ in a northern Ontario health centre 2012/13; half of the pregnant mothers involved enrolled in a narcotic replacement and tapering program involving long-acting morphine; by delivery, most (92\%) had reduced (92\%) or completely tapered $(9 \%)$ their morphine dose, although about half were still involved in PO misuse. The incidence of neonatal abstinence syndrome among participants was significantly lower $(P=.003)$ compared to a previous (2010) study conducted in the same setting (82).

\section{Conclusions}

In the above, we presented a review of key data and indicators on PO misuse, harms, and effects of interventions in Canada since 2010. Data and information on PO-related indicators in Canada have grown in re- cent years, even though systematic (e.g., nation-wide) monitoring and data on key indicators - for example PO-related mortality or treatment admissions, as routinely available in the US - remain absent (83). The examination of data since 2010 is distinctly pertinent, since a number of interventions to reduce PO-related harms have been implemented on both federal and provincial levels. While there have been indications of select reductions (e.g., NMPOU in general populations, high-dose PO dispensing) in some arenas, the causal contributions of individual interventions is difficult - if not impossible - to ascertain. In addition, a possible shift of key PO-related indicators - e.g., from high levels of oxycodone dispensing to other strong POs - may have begun to occur, and overall levels of PO dispensing and harms in Canada unquestionably remain high, also in global comparison. While the amount of relevant studies and information has rapidly increased from previous periods, the aggregate of data on PO-related indicators in Canada continues to be highly fragmented and patchwork-like, and is, in many instances, limited to singular studies or analyses (1). Notwithstanding the piecemeal nature of available information, there remains significant concern about the high overall annual consumption rate of POs in Canada, indicating further increases to the already high annual consumption levels in recent years. Additionally, PO-related mortality rates appear to have climbed in a number of provincial jurisdictions. Some population-level measures and interventions that have been introduced since 2010 appear to show promise and potentially initial effects in reducing PO-related harm outcomes in select sub-jurisdictions (e.g., Ontario). These include the introduction of PMPs, delisting of specific POs, and targeted educational programs for physicians that address narcotics prescription $(9,75,77)$. While some of the developments observed may reflect recent trends described for the US - where recent trends for key PO-related harm indicators have either plateaued or begun to decrease around 2010 $(5,6)$ - it is too early, and data are too limited to conclude whether similar developments are occurring across Canada. Given the persistently extensive public health burden associated with PO use and harms, and the dire need to understand both determinants and causes of these harms as well as the effectiveness of interventions, relevant data and information ought to be generated and integrated much more systematically in Canada. Beyond primarily investigator-driven studies, there should be a concerted, government-supported national initiative to generate and monitor relevant 
key indicators for systematic monitoring purposes, and to conduct evaluation and impact studies on key interventions.

\section{Acknowledgments}

The authors acknowledge research funding from the Canadian Institutes of Health Research (CIHR), specifically Team Grant SAF-94814 and Population Health Intervention Grant GIR-109852, supporting the development of this manuscript. BF furthermore acknowledges salary support from a CIHR/PHAC Chair in Applied Public Health. Neither the funding bodies nor the sources of external data used for analysis had any role in the analysis and interpretation of data; in the writing of the manuscript; or in the decision to submit the manuscript for publication. The authors have no conflicts of interest to declare.

\section{References}

1 Fischer B, Argento E. Prescription opioid related misuse, harms, diversion and interventions in Canada: A review. Pain Physician 2012; 15:ES191-ES2O3.

2. Fischer B, Keates A, Buhringer G, Reimer J, Rehm J. Non-medical use of prescription opioids and prescription opioid-related harms: Why so markedly higher in North America compared to the rest of the world? Addiction 2014; 109:177-181.

3. Volkow ND, McLellan TA. Curtailing diversion and abuse of opioid analgesics without jeopardizing pain treatment. JAMA 2011; 305:1346-1347.

4. Manchikanti L, Atluri S, Hansen $\mathrm{H}, \mathrm{Be}-$ nyamin RM, Falco FJ, Helm li S, Kaye $A D$, Hirsch JA. Opioids in chronic noncancer pain: Have we reached a boiling point yet? Pain Physician 2014; 17:1-10.

5. Atluri S, Sudarshan G, Manchikanti L. Assessment of the trends in medical use and misuse of opioid analgesics from 2004 to 2011. Pain Physician 2014; 17:E119-E128.

6. Dart RC, Surratt HL, Cicero TJ, Parrino MW, Severtson SG, Bucher-Bartelson B, Green JL. Trends in opioid analgesic abuse and mortality in the United States. N Engl J Med 2015; 372:241-248.

7. International Narcotics Control Board (INCB). Narcotic Drugs Estimated World Requirements for 2014 - Statistics for 2012. 2014; T.14.XI.2.

8. Morgan S, Smolina K, Mooney D, Raymond C, Bowen M, Gorczynski C, Rutherford K. The Canadian Rx Atlas. 3rd edition. Centre for Health Services and Policy Research, Vancouver, 2013.

9. Fischer B, Jones W, Rehm J. Trends and changes in prescription opioid analgesic dispensing in Canada 2005-2012: An update with a focus on recent interventions. BMC Health Serv Res 2014; 14:90.

10. Gomes T, Mamdani MM, Paterson JM, Dhalla IA, Juurlink DN. Trends in high- dose opioid prescribing in Canada. Can Fam Physician 2014; 60:826-832

11. Health Canada. Canadian Alcohol and Drug Use Monitoring Survey (CADUMS): Summary of Results for 2012. 2014; Available at: www.hc-sc.gc.ca/hc-ps/ drugs-drogues/stat/_2012/summarysommaire-eng.php. Accessed May 1, 2014.

12. Ialomiteanu A, Hamilton H, Adlaf E, Mann R. CAMH Monitor ereport: Substance use, mental health and well-being among Ontario adults, 1977-2013. 2014; CAMH Research Document Series No. 40.

13. Patented Medicine Prices Review Board (PMPRB). Utilization of Prescription Opioids in Canada's Public Drug Plans, 2006/07 to 2012/13. 2014.

14. Gomes T, Juurlink DN, Dhalla IA, MailisGagnon A, Paterson JM, Mamdani MM. Trends in opioid use and dosing among socio-economically disadvantaged patients. Open Med 2011; 5:e13-e22.

15. Allen MJ, Asbridge MM, Macdougall PC, Furlan AD, Tugalev O. Self-reported practices in opioid management of chronic noncancer pain: A survey of $\mathrm{Ca}$ nadian family physicians. Pain Res Manag 2013; 18:177-184.

16. Clarke H, Soneji N, Ko DT, Yun L, Wijeysundera DN. Rates and risk factors for prolonged opioid use after major surgery: Population based cohort study. BM] 2014; 348:g1251.

17. Kraut A, Shafer LA, Raymond CB. Proportion of opioid use due to compensated workers' compensation claims in Manitoba, Canada. American Journal of Industrial Medicine 2015; 58:33-39.

18. Gagnon B, Scott S, Nadeau L, Lawlor PG. Patterns of community-based opioid prescriptions in people dying of cancer. J Pain Symptom Manage 2015; 49:36-44.

19. Kurdyak P, Gomes T, Yao Z, Mamdani MM, Hellings C, Fischer B, Rehm J, Bay- oumi AM, Juurlink DN. Use of other opioids during methadone therapy: A population-based study. Addiction 2012; 107:776-780.

20. Nosyk B, Fischer B, Sun H, Marsh D, Kerr T, Rehm J, Anis A. High levels of opioid analgesic co-prescription among methadone maintenance treatment clients in British Columbia, Canada: Results from a population-level retrospective cohort study. Am J Addict 2014; 23:257-264

21. Voon P, Callon C, Nguyen P, Dobrer S, Montaner JS, Wood E, Kerr T. Denial of prescription analgesia among people who inject drugs in a Canadian setting. Drug Alcohol Rev 2015; 34:221-228.

22. Health Canada. Canadian Alcohol and Drug Use Monitoring Survey (CADUMS): Summary of Results for 2011. 2012; Available at: www.hc-sc.gc.ca/hc-ps/ drugs-drogues/stat/_2011/summarysommaire-eng.php. Accessed November 23, 2012.

23. Fischer B, lalomiteanu A, Boak A, Adlaf E, Rehm J, Mann R. Prevalence and key covariates of non-medical prescription opioid use among the general secondary student and adult populations in Ontario, Canada. Drug Alcohol Rev 2013; 32:276-287.

24. Currie CL, Schopflocher DP, Wild TC. Prevalence and correlates of 12-month prescription drug misuse in Alberta. Can J Psychiatry 2011; 56:27-34.

25. Health Canada. Summary of Results of the 2012-13 Youth Smoking Survey. 2014; Available at: www.hc-sc.gc.ca/ hc-ps/tobac-tabac/research-recherche/ stat/_survey-sondage_2012-2013/resulteng.php. Accessed 01/07, 2015.

26. Boak A, Hamilton HA, Adlaf EM, Mann RE. Drug Use among Ontario Students, 1977-2013: Detailed OSDUHS Findings (CAMH Research Document Series No. 36). 2013. 
27. Smith A, Stewart D, Poon C, Peled M, Saewyc E; McCreary Centre Society. From Hastings Street to Haida Gwaii: Provincial results of the 2013 BC Adolescent Health Survey. McCreary Centre Society, Vancouver, 2014

28. Asbridge $M$, Langille D. Nova Scotia Student Drug Use Survey 2012: Technical Report. Dalhousie University, Halifax, 2013.

29. Department of Health and Community Services. Newfoundland and Labrador 2012 Student Drug Use Survey: Highlights Report. Department of Health and Community Services, St. John's, 2013.

30. Gupta N, Wang H, Collette M, Pilgrim W. New Brunswick Student Drug Use Survey Report 2012. Department of Health, Fredericton, 2013.

31. Cheverie C, Henry S, MacSwain M, McClure C, Sanford C. Prince Edward Island Student Drug Use 2004-2011. Prince Edward Island Department of Health and Wellness, Charlottetown, 2013.

32. Public Health Agency of Canada. I-Track: Enhanced Surveillance of Risk Behaviours among People who Inject Drugs Phase I Report. Public Health Agency of Canada, Ottawa, 2006.

33. Public Health Agency of Canada. I-Track: Enhanced Surveillance of HIV, Hepatitis $\mathrm{C}$ and associated risk behaviours among people who inject drugs in Canada. Phase 2 Report. Public Health Agency of Canada, Ottawa 2014.

34. Argento E, Chettiara J, Nguyena P, Montanera J, Shannon K. Prevalence and correlates of nonmedical prescription opioid use among a cohort of sex workers in Vancouver, Canada. Int ] Drug Policy 2015; 26:59-66.

35. Kouyoumdjian FG, Calzavara LM, Kiefer L, Main C, Bondy SJ. Drug use prior to incarceration and associated sociobehavioural factors among males in a provincial correctional facility in Ontario, Canada. Can J Public Health 2014; 105:e198-e2O2.

36. The First Nations Information Governance Centre. First Nations Regional Health Survey (RHS) Phase 2 (2008/10) National Report on Adults, Youth and Children Living in First Nations Communities. The First Nations Information Governance Centre, Ottawa, 2012.

37. Katt M, Chase C, Samokhvalov AV, Argento E, Rehm J, Fischer B. Feasibility and outcomes of a community-based taper-to-low-dose-maintenance suboxone treatment program for prescription opioid dependence in a remote First Nations community in northern Ontario. J Aborig Health 2012; 9:52.

38. Currie CL, Wild TC. Adolescent use of prescription drugs to get high in Canada. Can J Psychiatry 2012; 57:745-751.

39. Drug and Alcohol Treatment Information System (DATIS). Substance Abuse Statistical Tables: Fiscal Year 2007/2008 to Fiscal Year 2012/2013. 2013.

40. Fischer B, Jones W, Rehm J. High correlations between levels of consumption and mortality related to strong prescription opioid analgesics in British Columbia and Ontario, 2005-2009. Pharmacoepidemiol Drug Saf 2013; 22:438-442.

41. Hadland SE, DeBeck K, Kerr T, Feng C, Montaner JS, Wood E. Prescription opioid injection and risk of hepatitis $C$ in relation to traditional drugs of misuse in a prospective cohort of street youth. BMJ Open 2014; 4:e005419

42. Bruneau J, Roy E, Arruda N, Zang G, Jutras-Aswad D. The rising prevalence of prescription opioid injection and its association with hepatitis $C$ incidence among street-drug users. Addiction 2012; 107:1318.

43. Turner S, Gomes T, Camacho X, Yao Z, Guttmann A, Mamdani MM, Juurlink DN, Dhalla IA. Neonatal opioid withdrawal and antenatal opioid prescribing. CMA] 2015; 3:E55-E61.

44. Kelly L, Guilfoyle J, Dooley J, Antone I, Gerber-Finn L, Dooley R, Brunton N, Kakegamuck K, Muileboom J, Hopman W, Cromarty H, Linkewich B, Maki J. Incidence of narcotic abuse during pregnancy in northwestern Ontario: Threeyear prospective cohort study. Can Fam Physician 2014; 60:493-498.

45. Kelly L, Dooley J, Cromarty H, Minty B, Morgan A, Madden S, Hopman W. Narcotic-exposed neonates in a First $\mathrm{Na}$ tions population in northwestern Ontario: Incidence and implications. Can Fam Physician 2011; 57:e441-e447.

46. Asbridge M, Cartwright J, Langille D. Driving under the influence of opioids among high school students in Atlantic Canada: Prevalence, correlates, and the role of medical versus recreational consumption. Accid Anal Prev 2014; 75C:184-191.

47. Gomes T, Redelmeier DA, Juurlink DN, Dhalla IA, Camacho X, Mamdani MM. Opioid dose and risk of road trauma in Canada: A population-based study.
JAMA Internal Medicine 2013; 173:196-201.

48. Office of the Chief Coroner (Ontario). Office of the Chief Coroner Report for 2009-2011. 2012.

49. Office of the Chief Coroner (Ontario). Number of Opioid Related Deaths by Drug 2002-2013. 2014.

50. Gomes T, Mamdani MM, Dhalla IA, Cornish S, Paterson JM, Juurlink DN. The burden of premature opioid-related mortality. Addiction 2014; 109:1482-1488.

51. Madadi P, Hildebrandt D, Lauwers AE, Koren G. Characteristics of opioid-users whose death was related to opioid-toxicity: A population-based study in Ontario, Canada. PLoS One 2013; 8:e60600.

52. Fischer B, Jones W, Urbanoski K, Skinner $\mathrm{R}$, Rehm J. Correlations between prescription opioid analgesic dispensing levels and related mortality and morbidity in Ontario, Canada, 2005-2011. Drug Alcohol Rev 2013; 33:19-26.

53. Gomes T, Juurlink DN, Moineddin R, Gozdyra P, Dhalla I, Paterson M, Mamdani MM. Geographical variation in opioid prescribing and opioid-related mortality in Ontario. Healthc $Q$ 2011; 14:22-24.

54. BC Coroners Service. Prescription opiate-related overdose deaths 2005-2010. 2013.

55. BC Coroners Service. Fentanyl-detected deaths in illicit drug circumstances 2012 -2014(YTD). 2014.

56. BC Coroners Service. Illicit drug overdose deaths in BC 2009-2013. 2014.

57. Gagné $M$, Dube PA, Perron PA, Langlois E, Legare G, Sirois MJ, Aubut C, Lefebvre M, St.Laurent M. Opioid-related poisoning deaths in Québec: 2000 to 2009. Institut National de Santé Publique du Québec, Québec, 2013.

58. Fisher J, Urquhart R, Johnston G. Use of opioid analgesics among older persons with colorectal cancer in two health districts with palliative care programs. ] Pain Symptom Manage 2013; 46:20-29.

59. Kahan $M$, Wilson $L$, Mailis-Gagnon A, Srivastava A; National Opioid Use Guideline Group. Canadian guideline for safe and effective use of opioids for chronic noncancer pain: Clinical summary for family physicians. Part 2: Special populations. Can Fam Physician 2011; 57:1269-1276.

6o. Furlan AD, Reardon R, Weppler C, for the National Opioid Use Guideline Group (NOUGG). Opioids for chronic noncancer pain: A new Canadian practice guideline. CMA] 2010; 182:923-930. 
61. Weeks C. OxyContin delisting not the answer to opioid addiction, experts say. The Globe and Mail . February 26, 2012.

62. Fischer B, Keates A. 'Opioid drought', Canadian-style? Potential implications of the 'natural experiment' of delisting Oxycontin in Canada. Int J Drug Policy 2012; 23:495-497.

63. Furlan $A D$, MacDougall $P$, Pellerin $D$, Shaw K, Spitzig D, Wilson G, Wright J. Overview of four prescription monitoring/review programs in Canada. Pain Research \& Management 2014; 19:102-106.

64. Ministry of Health and Long Term Care. Ontario's Narcotics Monitoring System. 2012; Available at: http://news.ontario. $\mathrm{ca} / \mathrm{mohltc} / \mathrm{en} / 2012 / 05 /$ ontarios-narcotics-monitoring-system.html. Accessed 02/07, 2015.

65. National Advisory Committee on Prescription Drug Misuse. First Do No Harm: Responding to Canada's Prescription Drug Crisis. Canadian Centre on Substance Abuse, Ottawa, 2013.

66. Expert Working Group on Narcotic Addiction. The Way Forward: Stewardship for Prescription Narcotics in Ontario. Ontario Ministry of Health and LongTerm Care, Concord, 2012.

67. Health Canada. Consultation on the Draft Guidance Document: TamperResistant Formulations of Opioid Drug Product Submissions. 2014; Available at: www.hc-sc.gc.ca/dhp-mps/consultation/drug-medic/consult_draft_guid_ opioid_ebauche_ld-eng.php. Accessed 02/07, 2015.

68. CBC News. Opioid painkillers to get stronger warning labels, Health Minister says. CBC News 2014.

69. King S. OxyContin in Ontario: The multiple materialities of prescription pain- killers. Int J Drug Policy 2014; 25:486-493.

70. Borwein A, Kephart G, Whelan E, Asbridge $M$. Prescribing practices amid the oxycontin crisis: Examining the effect of print media coverage on opioid prescribing among physicians. J Pain 2013; 14:1686-1693.

71. Fischer B, Jones W, Murphy Y, lalomiteanu A, Rehm J. Recent Developments in Prescription Opioid-related Dispensing and Harm Indicators in Ontario, Canada. Pain Physician in press.

72. Ministry of Health and Long-Term Care. A Review of the Impacts of Opiate Use in Ontario: Interim Summary Report. 2013.

73. Ministry of Health and Long-Term Care. A Review of the Impacts of Opiate Use in Ontario: Summary Report. 2013.

74. Dormuth $C R$, Miller TA, Huang $A$, Mamdani MM, Juurlink DN. Effect of a centralized prescription network on inappropriate prescriptions for opioid analgesics and benzodiazepines. CMA] 2012; 184:E852-E856.

75. Gomes T, Juurlink D, Yao Z, Camacho X, Paterson JM, Singh S, Dhalla I, Sproule B, Mamdani M. Impact of legislation and a prescription monitoring program on the prevalence of potentially inappropriate prescriptions for monitored drugs in Ontario: A time series analysis. CMA] Open 2014; 2:256-261.

76. Fisher JE, Zhang Y, Sketris I, Johnston $G$, Burge F. The effect of an educational intervention on meperidine use in Nova Scotia, Canada: A time series analysis. Pharmacoepidemiol Drug Saf 2012; 21:177-183

77. Kahan M, Gomes T, Juurlink DN, Manno M, Wilson L, Mailis-Gagnon A, Srivastava A, Reardon R, Dhalla IA, Mamdani MM. Effect of a course-based intervention and effect of medical regulation on physicians' opioid prescribing. Canadian Family Physician 2013; 59:231-239.

78. Srivastava A, Kahan M, Jiwa A. Prescription opioid use and misuse piloting an educational strategy for rural primary care physicians. Canadian Family Physician 2012; 58:e210-e216.

79. Gomes T, Paterson JM, Juurlink DN, Dhalla IA, Mamdani MM. Reformulation of controlled-release oxycodone and pharmacy dispensing patterns near the US-Canada border. Open Med 2012; 6:141-145.

8o. Handford C, Kahan M, Srivastava A, Cirone S, Palda V. Buprenorphine/Naloxone for Opioid Dependence: Clinical Practice Guideline. Centre for Addiction and Mental Health, Toronto, 2011.

81. Kanate D, Folk D, Cirone S, Gordon J, Kirlew M, Veale T, Bocking N, Rea S, Kelly L. Community-wide measures of wellness in a remote First Nations community experiencing opioid dependence: Evaluating outpatient buprenorphine-naloxone substitution therapy in the context of a First Nations healing program. Can Fam Physician 2015; 61:160-165.

82. Dooley R, Dooley J, Antone I, Guilfoyle J, Gerber-Finn L, Kakekagumick K, Cromarty H, Hopman W, Muileboom J, Brunton N, Kelly L. Narcotic tapering in pregnancy using long-acting morphine: An 18-month prospective cohort study in northwestern Ontario. Can Fam Physician 2015; 61:E88-E95.

83. Fischer B, Gooch J, Goldman B, Kurdyak P, Rehm J. Non-medical prescription opioid use, prescription opioid-related harms and public health in Canada: A update 5 years later. Can J Public Health 2014; 105:146-149. 